\title{
THEORY AND LABORATORY OBSERVATIONS OF NALED ICE GROWTH
}

\author{
By G. A. SCHOHL and R. ETTEMA \\ (Iowa Institute of Hydraulic Research, Department of Civil and Environmental Engineering, University of \\ lowa. Iowa City, Iowa 52242, U.S.A.)
}

\begin{abstract}
Based on observations of naleds (also called aufeis or icings) grown in a refrigerated laboratory flume, a detailed, composite description of the processes associated with naled ice growth is presented. A spread length is derived that represents a mass balance between the water supplied to a naled's surface and the ice that freezes on to the surface. Herein, this spread length is termed an equilibrium length. Guided by this concept of equilibrium length and the laboratory. data, length- and time-scales applicable to the growth of two-dimensional naleds are proposed. These scales proved useful for normalizing the times and streamwise lengths that correspond to distinct phases of naled ice growth. It is observed that, even in a laboratory flume, naleds spread and thicken in a complex, layer-by-layer manner.

To the best of the authors' knowledge, this is the first reported laboratory study on naled ice growth. The descriptions and concepts presented herein should be useful to engineers concerned with the effects of naleds on engineering works, and of interest to those who are planning experiments on naleds.
\end{abstract}

RÉsumé. Théorie et observations de laboratoire pour la croissance de la glace de glaçage. En se basant sur des observations de glaçages (aussi appelés aufeis ou icings) qui croisent sur les tuyaux dans un laboratoire réfrigéré, on presente une description détaillee de leur processus de développement. On en déduit une longueur de développement qui représente un bilan de masse entre l'eau fournie à leur surface et la glace qui y gèle. C'est pourquoi cette longueur correspond à une longueur d'équilibre. Guidés par ce concept de longueur d'équilibre et par les données experimentales, on propose une longueur et des échelles de temps pour la croissance bidimentionnelle des glaçages. Ces echelles se sont révélées utile dans la normalisation du temps et des longueurs d'application qui définissent les différentes phases de croissance du glaçage. L'observation montre que,

\section{NOMENCLATURE}

Water or slush depth on the surface of a naled

$h \quad$ Heat-transfer coefficient

$k_{\mathrm{i}} \quad$ Thermal conductivity of ice

1 Stream-wise spread length of a naled

e Equilibrium length of a two-dimensional naled

Is Equilibrium length if $\phi_{\mathrm{i}}$ is neglected for naled growth

L Latent heat of fusion for water to ice

$m \quad$ Porosity of naled slush

Water discharge per unit width même sur les tuyaux de chambre froide, le glaçage se développe d'une façon complexe, couche par couche

A notre connaissance, c'est la première fois que sont décrites les études de laboratoire concernant la croissance $d u$ glaçage. Ces descriptions et concepts peuvent etre utiles aux ingénieurs qui ont a faire avec les effets de glaçage dans leur domaine, ainsi que pour ceux qui projettent des expériences sur le glaçage.

ZUSAMMENFASSUNG. Theorie und Laborbeobachtungen des Wachstums von Aufeis. Auf der Grundlage von Beobachtungen an Aufeis, gezogen in einem gekühlten Laborgerinne, wird eine genaue und vollstăndige Beschreibung der Prozesse, die mit dem Wachstum von Aufeis verbunden sind, gegeben. Es wird eine Ausbreitungslange hergeleitet, die einen Massenausgleich zwischen dem Wasser, das einer Aufeisoberflăche zugeführt wird, und dem Eis, das an der Oberflăche anfriert, darstellt. Deshalb wird diese Ausbreitungslănge als Gleichgewichtslănge bezeichnet. Im Hinblick auf dieses Konzept der Gleichgewichtslânge und die Labordaten werden Langenund Zeitskalen vorgeschlagen, die sich auf das Wachstum zweidimensionalen Aufeises anwenden lassen. Diese Skalen erweisen sich als natzlich for die Normalisierung der Zeiten und Stromlăngen, die verschiedenen Phasen des Aufeiswachstums entsprechen. Die Beobachtungen zeigen, dass Aufeis selbst in einem Laborgerinne sich auf eine komplexe, schichtweise Art ausbreitet und verdickt.

Soweit der Autor dies beurteilen kann, ist dies der erste Bericht über Laborstudien des Aufeiswachstums. Die dargebotenen Beschreibungen und Konzepte sollten für Ingenieure, die sich mit den Wirkungen von Aufeis auf Ingenieurbauten befassen, nützlich und für solche, die Versuche mit Aufeis planen, von Interesse sein. 
Heat flux

\section{Subscripts}

a $\quad$ Air

b Frigid base

f Freezing

i Ice

$0 \quad$ At $x=0$

s Water surface

w Water

wa Water to air

wi Water to underlying ice

\section{INTRODUCTION}

Theoretical formulation and observations of naled ice growth in a refrigerated laboratory flume are used here to describe the manner in which naled ice grows as a naled spreads and thickens.

Small-scale naleds were observed and monitored as they grew under conditions of steady discharge and heat-flux rates in a refrigerated flume located in the Low Temperature Flow Facility at the Iowa Institute of Hydraulic Research (IIHR). These flume naleds are herein termed "laterally confined" naleds because they were confined by the side walls of the flume and an up-stream gate so that they could spread only along the down-stream direction.

A simplified, or idealized, laterally confined naled is illustrated schematically in Figure 1 , in which a naled is depicted as a formation of ice covered by a shallow flow of water. Because its longitudinal cross-section is invariant across the width of the flume, and its shape is defined by a typical longitudinal, two-dimensional cross-section, the naled shown in Figure 1 may be considered to be twodimensional. The following terms can be used to describe the geometry of a two-dimensional naled: naled length, $\ell(t)$; thickness of naled that underlies the surface flow, $\eta(x, t)$; and the depth of water flow, $\mathrm{d}(x, t)$. The definition of a two-dimensional naled is useful for describing the energy budget for naled ice growth, and for deriving a naled spread length, termed the equilibrium length. The flume naleds were two-dimensional during their early growth but their later growth was influenced by three-dimensional, or boundary, effects. The growth of a naled in Nature is generally complicated by both unsteady and three-dimensional effects.

To the best of the authors' knowledge, these are the first laboratory experiments concerned with naled ice growth to be reported in the literature. The literature is well stocked with references that are largely anecdotal (e.g. Sloan and others, 1976; Baranowski, 1982), relating observations of natural naleds. There are also references that discuss the hydrological, meteorological, and geomorphological conditions that cause the formation of naleds (e.g. Sokolov, 1979; Kane, 1981; Wankiewicz, 1984). However, in the literature to date there appears to be neither a detailed description of naled ice growth nor a predictive formulation for estimating the dimensions to which a naled may spread and thicken. For an extensive review of the pre-1970 literature on naleds, the reader is referred to the annotated bibliography compiled by Carey (1970). For further description of naleds and more recent references, the reader is referred to Carey (1973), Alekseyev and others (1973), and Schohl and Ettema (1985).
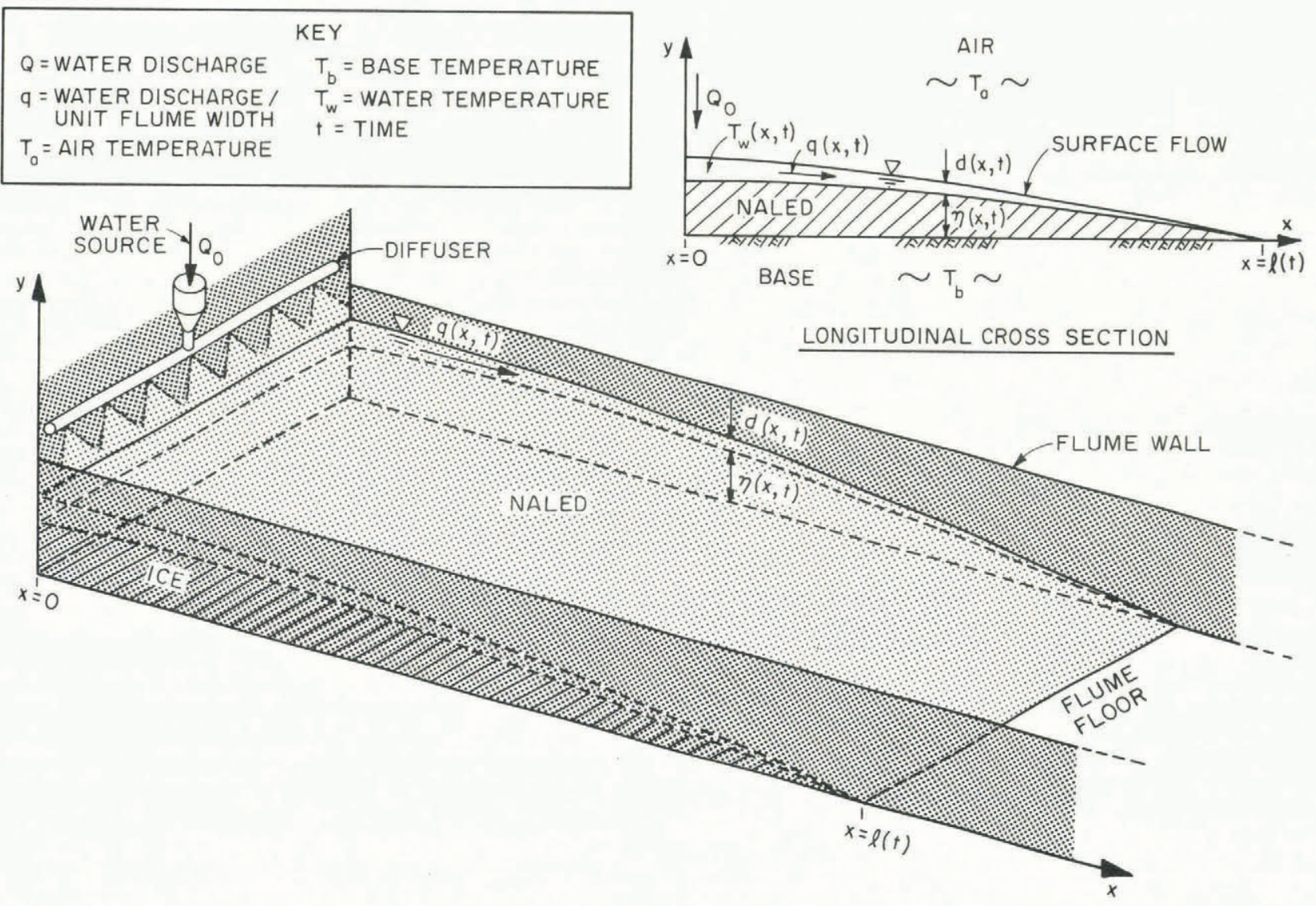

\section{LONGITUDINAL CROSS SECTION}

Fig. 1. Schematic of simplified, two-dimensional naled ice growth in the refrigerated flume. 


\section{NALED ICE GROWTH IN NATURE}

Naleds (also referred to as aufeis or icings) are spreading and thickening ice accretions that grow in cold winter air when a shallow flow of water streams over a river-ice cover, or over frozen ground, and freezes progressively to it. A naled can form initially on any frigid surface but its subsequent growth always proceeds as a progressive accretion of ice.

Naleds are commonly classified in accordance with their water source. The most common types of naled are river, spring, and ground naleds, which grow from river water, spring water, and ground water, respectively. Of these three classes of naleds, river naleds are usually the largest, of ten reaching 10 to $20 \mathrm{~km}$ in length and $1 \mathrm{~km}$ in width, with average thickness of $1.5-3.5 \mathrm{~m}$ (Alekseyev and others, 1973).

Naleds begin growing when an insulated flow path under an ice cover or underground is interrupted causing water to emerge to the surface and flow in frigid air. Two typical situations that can lead to naled ice growth are depicted schematically in Figure 2. When an ice cover on a shallow river freezes to the river bottom at a location where
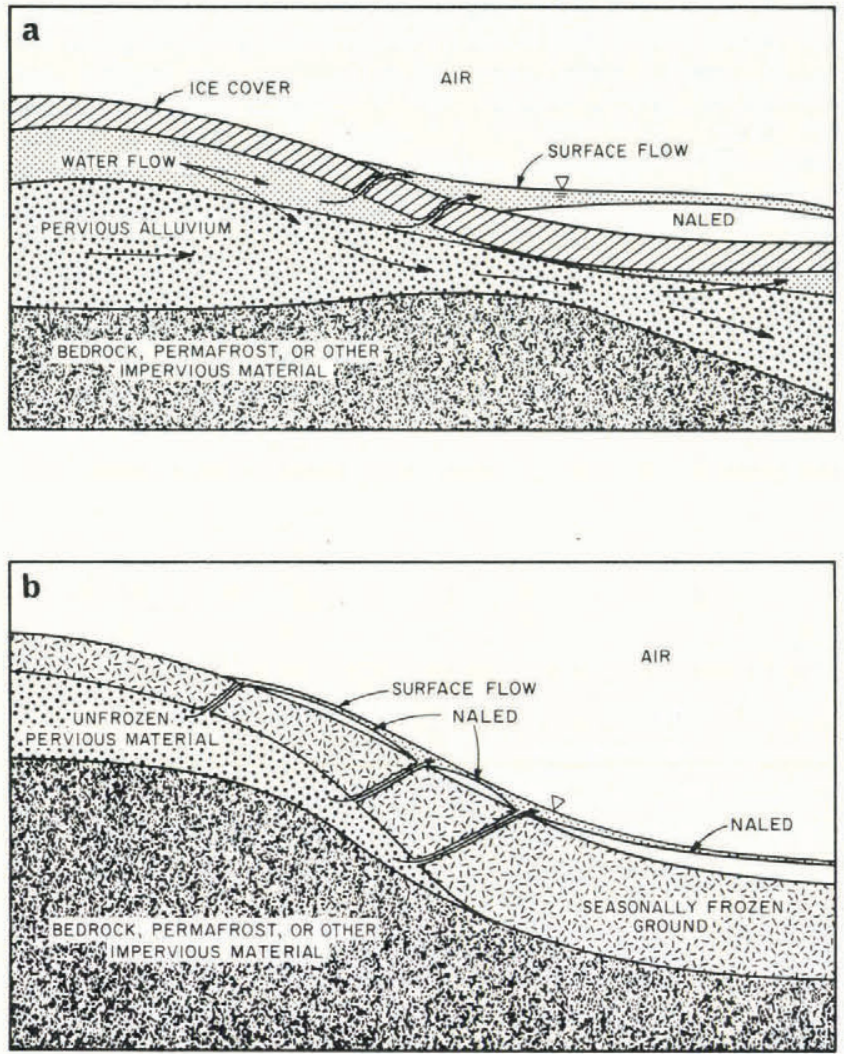

Fig. 2. Conditions that can lead to the development of naleds (adapted from Carey, 1973). (a) River naled; (b) Ground naled.

the underlying pervious alluvium cannot convey the entire discharge (Fig. 2a), the flow may become pressurized and seep through cracks in the ice cover and then flow over the ice cover. The flow spreads over and freezes on to the ice cover thereby forming a river naled. When the ground at the base of a hill (Fig. 2b) freezes sufficiently deep so as to intersect an underlying impervious material, the normal flow of ground water can be interrupted. The consequent pressure increase causes trapped water to seep to the surface, where it can form a ground naled. Water flow over a naled is typically shallow and laminar.

Man-made structures in the path of naleds may be threatened by them. Figure 3, for example, illustrates an instance where a river naled engulfed a small bridge.

In cross-section, naled ice is typically laminated. This feature is cited in many published descriptions of naled ice.
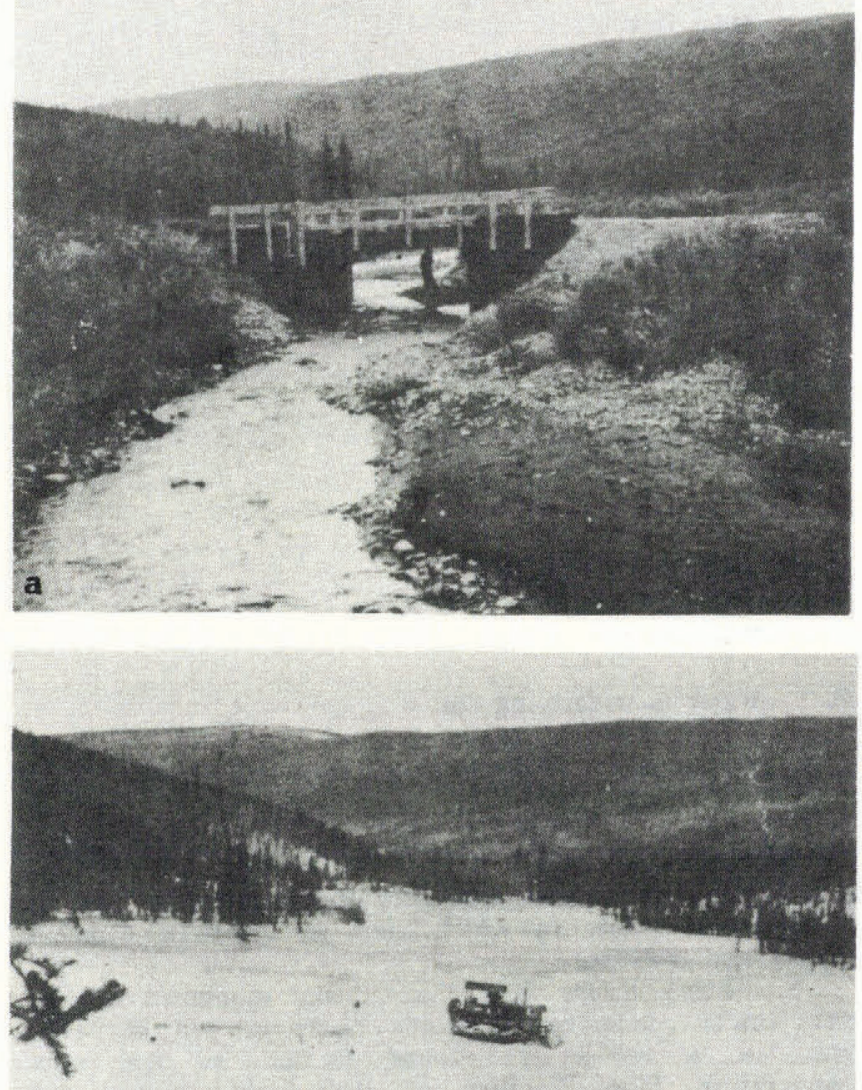

b

Fig. 3. Naled on a small river near Fairbanks, Alaska (from Carey, 1973). (a) Summer view; (b) Winter view (bridge railing is visible to left of tractor).

The laminations, or ice layers, are of ten irregular with respect to structure and color, and are of variable thickness, generally ranging from 1 to $40 \mathrm{~cm}$ (Alekseyev and others, 1973; Carey, 1973). Sloan and others (1976) presented a photograph. of a large sectional river naled with many laminations.

A naled in Nature is a three-dimensional ice formation. Its growth is governed by a complex, unsteady combination of factors (or independent variables) which include the following: the atmospheric conditions (air temperature, wind, net radiation, and evaporation) that affect heat transfer from the surface of the naled to the overlying air; the temperature and thermal conductivity of the underlying base, which govern the heat transfer from the underside of the naled; the topography of the surface over which the naled develops; the discharge, temperature, and spatial distribution of the water that issues on to the surface of the naled; and the amount of snow, or precipitation, that falls on to the naled.

The factors that describe the growth state of a naled (the dependent variables) include its lateral dimensions and thickness, and the discharge, temperature, and depth of liquid water over it. The lateral dimensions of a naled are functions of time; the other dependent variables are functions of both time and position on the naled.

\section{ENERGY BUDGET FOR NALED ICE GROWTH}

The heat fluxes and temperature profiles associated with water flowing over a simplified, two-dimensional ground naled are depicted in Figure 4. A similar figure could be shown for the heat fluxes associated with the 
(NOT TO SCALE)

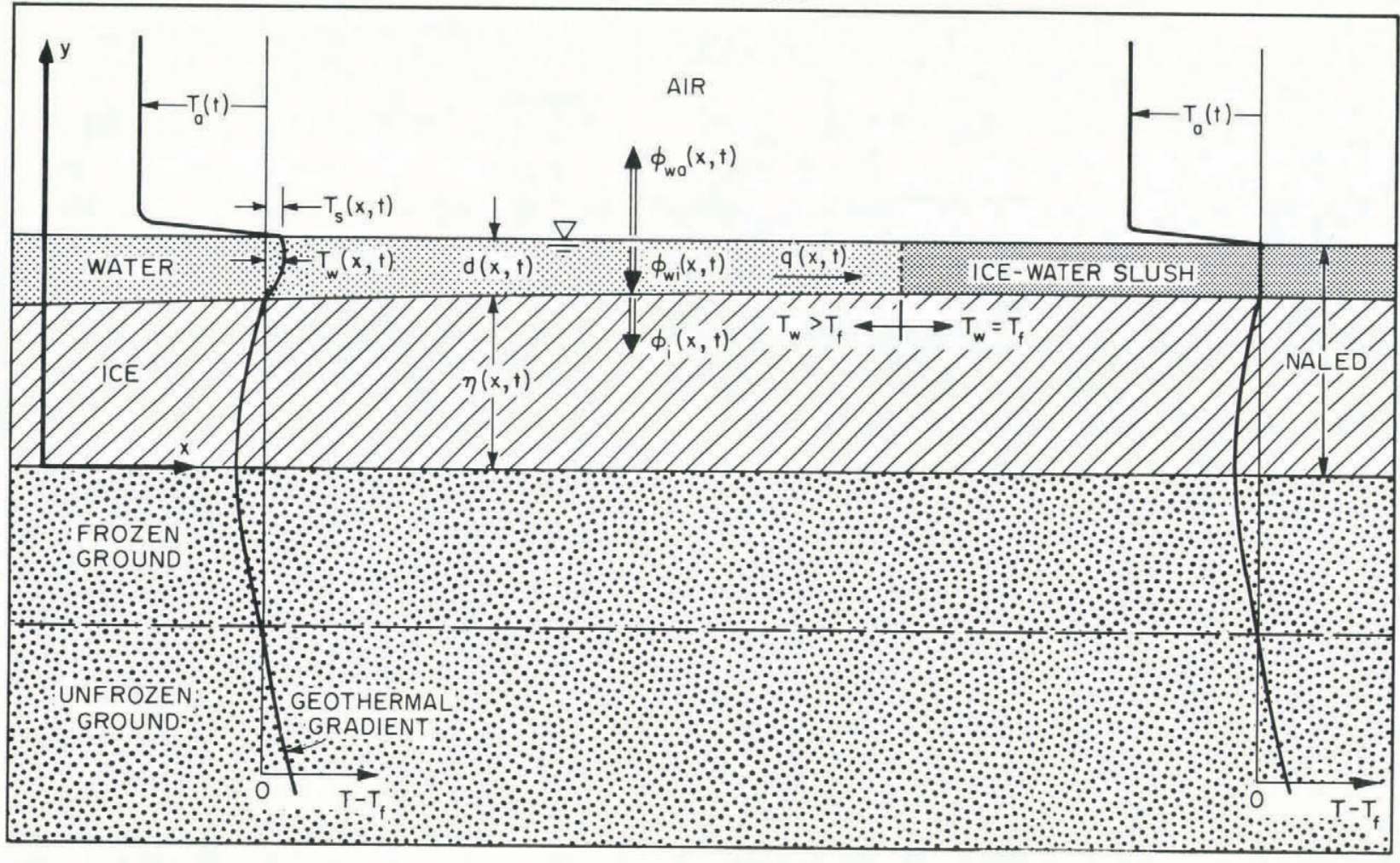

Fig. 4. Temperature profiles and heat-flux components for naled ice growth.

growth of a river naled. As water flows on a frigid base in frigid air, it gradually cools by losing heat to both the air above and to the base below (heat fluxes $\phi_{\mathrm{wa}}$ and $\phi_{\mathrm{wi}}$, respectively) until it reaches its freezing temperature $0^{\circ} \mathrm{C}$ for pure water. Because the water cannot cool further without ice growth, the additional heat lost from the water as it continues flowing is balanced by latent heat released when vertical, plate-like ice crystals, or platelets, grow from the ice base into the flow. The growth of ice platelets is discussed further in section 7. In addition to the growth of ice platelets within the flow, ice may either accrete or melt on the base, releasing or absorbing latent heat, depending on whether the heat flux through the base, $\phi_{i}$, is larger than or less than the heat flux from the water to the base, $\phi_{\mathrm{wi}}$.

In Figure 4 , temperature distributions are shown in both the up-stream region of flow and in the down-stream, ice-water slush region. These distributions differ only within the flow, in which the water temperature varies from $T_{\mathrm{f}}$ at the water-ice interface to $T_{\mathrm{S}}$ at the water surface. Up-stream, the bulk water temperature $T_{\mathrm{w}}$ is greater than $T_{\mathrm{f}}$. As the water flows down-stream, $T_{\mathrm{W}}$ is reduced until the water temperature equals $T_{\mathrm{f}}$ over the entire depth of flow.

In Nature, the air temperature $T_{\mathrm{a}}$ varies with time and with position over a naled. In the laboratory, $T_{\mathrm{a}}$ was held constant during naled ice growth.

The net heat flux from the water to the air, $\phi_{\text {wa }}$, is due to the combined effects of shortwave and longwave radiation, conduction and convection, evaporation, and precipitation. Because it is a complicated function of meteorological conditions, $\phi_{\mathrm{wa}}$ is usually expressed semiempirically as a function of the water-surface and air temperatures:

$$
\phi_{\mathrm{wa}}(x, t)=h_{\mathrm{wa}}(x, t)\left[T_{\mathrm{s}}(x, t)-T_{\mathrm{a}}(x, t)\right],
$$

in which $h_{\text {wa }}$ is a heat-transfer coefficient which depends on meteorological conditions. Ashton (1978) suggested an average value for $h_{w a}$ of $25 \mathrm{~W} / \mathrm{m}^{2} \mathrm{deg}$ for open-water conditions. Bengtsson (1982) measured a value of $12 \mathrm{~W} / \mathrm{m}^{2} \mathrm{deg}$ in a laboratory cold room.
The convective heat flux from the water to the icewater interface, $\phi_{\text {wi }}$, can be expressed as

$$
\phi_{\mathrm{wi}}(x, t)=h_{\mathrm{wi}}(x, t)\left[T_{\mathrm{w}}(x, t)-T_{\mathrm{f}}\right] .
$$

The problem of determining $\phi_{w i}$ is actually a problem of determining the heat-transfer coefficient, $h_{\text {wi. }}$. Empirical formulae are available for evaluating $h_{\mathrm{wi}}$ as a function of flow geometry, a Reynolds number, and the Prandtl number (e.g. see Haynes and Ashton, 1979). In water that is warmer than $T_{\mathrm{f}}, \phi_{\text {wi }}$ acts to reduce water temperature.

As indicated in Figure 4, the temperature of the ice beneath the water-ice interface is less than or equal to $T_{\mathrm{f}}$. Consequently, under the assumption that $\phi_{\mathrm{i}}$ is conductive, the heat transfer from the water-ice interface into the ice (of thermal conductivity, $k_{\mathrm{i}}$ ) can be stated as

$$
\phi_{\mathrm{i}}(x, t)=\left.k_{\mathrm{i}} \frac{\partial T}{\partial y}\right|_{y=\eta}(x, t),
$$

in which $\phi_{\mathrm{i}}$ is assumed to be directed vertically downward (for small longitudinal slopes). For the laboratory naleds, illustrated in Figure 1, $\phi_{i}$ is expressed as

$$
\phi_{\mathrm{i}}(x, t)=\frac{T_{\mathrm{f}}-T_{\mathrm{b}}}{\eta(x, t) / k_{\mathrm{i}}+1 / h_{\mathrm{b}}},
$$

in which $h_{\mathrm{b}}$ is the convective heat-transfer coefficient for heat flux into the flume floor $\left(h_{\mathrm{b}} \approx 225 \mathrm{~W} / \mathrm{m}^{2} \mathrm{deg}\right.$; Ashton, 1971; Hsu, 1973) and $T_{\mathrm{b}}$ is the temperature of the coolant fluid that circulates under the flume floor. It is assumed for Equation (4) that the entire thickness $\eta$ is composed of solid ice. The change of $\eta$ with respect to time is sufficiently slow to neglect the heat capacity of the naled ice and initial ice base, and to assume quasi-steady heat conduction.

For naleds in Nature, $\phi_{i}$ is small, perhaps even negligible, compared to $\phi_{\mathrm{wa}}$ (e.g. refer to Gavrilova (1973)). 
In fact, as illustrated in Figure $2 a$, river naleds of ten overlie unfrozen water and, consequently, their temperature is $T_{\mathrm{f}}$ throughout such that $\phi_{\mathrm{i}}$ is zero. Also, as discussed in section 8 , a naled may have layers of slush (at temperature $T_{\mathrm{f}}$ ) sandwiched between solid layers of ice, with the result that much of the naled is isothermal at $T_{\mathrm{f}}$ and, for the surface layer of slush, $\phi_{\mathrm{i}}$ is zero.

The elevation of the water-ice interface, $\eta$, varies as ice either accretes or melts, releasing or absorbing heat, to balance the difference between the heat fluxes $\phi_{w i}$ and $\phi_{\mathrm{i}}$. The temperature of the water-ice interface is always $T_{\mathrm{f}}$. If the density of ice is designated as $\rho_{i}$ and the latent heat of fusion for water as $L$, the interface energy budget can be expressed as an equation for the rate of change of $n$ :

$$
\frac{\partial n}{\partial t}(x, t)=\frac{\phi_{\mathrm{i}}(x, t)-\phi_{\mathrm{Wi}}(x, t)}{\rho_{\mathrm{i}} L} .
$$

It is evident from Equation (5) that if $\phi_{i}$ is greater than $\phi_{\text {wi }}$, ice will accrete on the interface. Conversely, if $\phi_{j}$ is less than $\phi_{w i}$, ice will melt at the interface. If the surface flow is slushy $\left(T_{\mathrm{w}}=T_{\mathrm{f}}\right), \phi_{\mathrm{wi}}$ will be zero, and the interface elevation will change in accordance with $\phi_{\mathrm{i}}$. If, as mentioned above, $\phi_{\mathrm{i}}$ is also zero, then the interface elevation will be constant and the naled ice will be isothermal at $T_{\mathrm{f}}$.

Ice crystals in the form of ice platelets grow throughout the surface flow through slush ice, as depicted in Figure 4. The balance between the heat flux from the naled surface to the air, $\phi_{w a}$, and the latent heat of fusion that is released as the ice platelets grow can be stated as

$$
\frac{\partial \Psi_{\mathrm{i}}(x, t)}{\partial t}=\frac{\phi_{\mathrm{wa}}(x, t)}{\rho_{\mathrm{i}} L}
$$

in which ${ }_{i}=$ the volume of ice platelets per unit surface area of the slush layer exposed to the air. Equation (6) may be used to estimate the volume of ice platelets in the naled slush at any position and time.

Consider the region in Figure 4 where $T_{\mathrm{w}}$ exceeds $T_{\mathrm{f}}$ (up-stream from the slushy region). Because $T_{\mathrm{w}}$ decreases as the water flows down-stream, $\phi_{\text {wi }}$ also decreases, as is shown in Equation (2). If $\phi_{i}$ is considered to be essentially constant, then Equation (5) indicates that the rate of ice accretion on the interface increases with increasing $x$, so the water-ice interface develops an adverse slope which becomes increasingly adverse with the passage of time. Calculation of $\eta(x, t)$ and $T_{\mathrm{w}}(x, t)$ in this region requires the simultaneous solution of the conservation of mass, momentum, and thermal energy equations for single-phase flow of water, and Equation (5) for the interface elevation, subject to Equations (1) and (3) as boundary conditions (see Schohl and Ettema, 1986).

\section{EQUILIBRIUM LENGTH OF A NALED}

The longitudinal length to which a naled spreads depends primarily on the magnitudes of the source-water discharge and the heat fluxes $\phi_{\mathrm{wa}}$ and $\phi_{\mathrm{i}}$.

When a flow spreads out over a naled, it may eventually reach a length at which the rate of water freezing is equal to the rate at which water is supplied. In other words, for this length of spread, the source-water discharge is equal to, or in equilibrium with, the rate at which water is freezing. Therefore, this length may be thought of as an equilibrium length, albeit a temporary one, for the streamwise spreading of the naled. For a simplified, two-dimensional naled, this length of spreading, which is later referred to as the equilibrium length, can be derived from the conservation-of-mass principle. The equilibrium length serves as a useful length scale for describing naled growth.

Because much of the surface of a growing naled is likely to be covered by ice-water slush rather than by water alone (as described in section 8), it is assumed that slush covers the entire surface of a naled. The ice slush is considered to be a porous medium with porosity $m$ defined as the volume of water in the medium to the total volume of the medium. Under these assumptions, the conservationof-mass principle applied to the flow over a simplified, two-dimensional naled (as depicted in Figure 4) yields

$$
\frac{\partial q}{\partial x}+\frac{\partial(m d)}{\partial t}+\frac{\rho_{i} \partial}{\rho_{w} \partial t}\left(n+\boldsymbol{H}_{i}\right)=0
$$

in which $\rho_{w}$ is water density. If Equations (5) and (6) are substituted (with $\phi_{\text {wi }}=0$ ), Equation (7) becomes

$$
\frac{\partial q}{\partial x}+\frac{\partial(m d)}{\partial t}+\frac{\phi_{\mathrm{wa}}+\phi_{i}}{\rho_{\mathrm{w}} L}=0 .
$$

This equation reflects the fact that, in frigid air, the water discharge, $q$, over a two-dimensional naled diminishes with distance along the naled's surface because water is continually removed from the flow to grow ice (third term in Equation (8)), and because water ponds (second term) when ice growth in the slushy surface flow becomes an increasing impedance to the flow. The effects of snowfall, evaporation, and condensation have been neglected for Equation (8). These effects may sometimes be significant for natural naleds.

If the rate of water that is freezing along a naled's surface is equal to the rate of water supplied to the naled, then no water should be accumulating within the naled slush. This suggests that $\partial(m d) / \partial t$ should be zero. If it is assumed that $\partial(m d) / \partial t=0$, and it is further assumed that $\phi_{\mathrm{wa}}, \phi_{\mathrm{i}}$, and $q_{0}$ are constants, then Equation (8) can be integrated from $x=0, q=q_{0}$ to $x=l_{\mathrm{e}}, q=0$ in order to obtain an expression for the equilibrium length, $\ell_{\mathrm{e}}$ :

$$
\ell_{\mathrm{e}}=\frac{q_{0} \rho_{\mathrm{W}} L}{\phi_{\mathrm{wa}}+\phi_{\mathrm{i}}}
$$

Equation (9) was derived for a two-dimensional naled growing under conditions of steady source-water discharge and heat flux. By applying the conservation-of-mass principle to the two-dimensional surface of a naled, the concept of an equilibrium spread length for two-dimensional naleds can be broadened to define an equilibrium spread area for three-dimensional naleds, over which water is flowing in several directions. However, in Nature, naleds probably never grow under steady conditions. In order to define an equilibrium length or an equilibrium area for naleds in Nature, it would be necessary to use space- and time-averaged values of $q_{0}, \phi_{\mathrm{wa}}$, and $\phi_{\mathrm{i}}$.

As they grew, the laboratory naleds developed adjacent solid laminations of ice and alternating layers of solid and slush ice (described in section 8). This process was governed principally by the heat flux from the water surface to the air, $\phi_{\text {wa }}$. The heat flux through the frigid base, $\phi_{i}$, played a secondary role. The experimental results indicate that the spread length obtained by omitting the heat flux $\phi_{i}$ in Equation (9),

$$
\imath_{\mathrm{s}}=\frac{q_{0} \rho_{\mathrm{w}} L}{\phi_{\mathrm{wa}}} \text {, }
$$

is a more satisfactory length scale than $\ell_{\mathrm{e}}$ for the purpose of describing the distinct phases of naled ice growth observed in the laboratory. For the relatively small values of $\phi_{\mathrm{i}}$ likely to occur in Nature, $\ell_{\mathrm{s}}$ and $\ell_{\mathrm{e}}$ may be nearly equal; but for the moderate values of $\phi_{\mathrm{i}}$ used in the experiments, $\ell_{s}$ and $\ell_{\mathrm{e}}$ were often significantly different.

The spread lengths $\ell_{s}$ and $\ell_{e}$ are physically meaningful approximations of the extent to which a laterally confined naled could develop during different phases of ice growth under given external conditions. For the maximum stream-wise extent of a naled during its first phase of growth, before the slush on its surface begins to freeze solid, $\ell_{e}$ is an appropriate estimate. But, for the maximum stream-wise extent of a naled during the later phases of its growth, as it accumulates layer by layer $\ell_{s}$ may be a more 
appropriate estimate, because at times the flow becomes insulated from $\phi_{\mathrm{i}}$. However, the spread length attained by a laterally confined naled will possibly be larger than both $\ell$ and $\ell_{s}$ for reasons that include the following: in a naled, some water will often flow through slush layers that are insulated from the heat flux $\phi_{\text {wa }}$, the heat flux $\phi_{\mathrm{i}}$, or both; the surface water may not flow uniformly over all regions of a naled (local dry spots may be present); and, in Nature, naleds grow usually from unsteady source-water discharges under unsteady meteorological conditions.

It was observed during the experiments (described below) that, for the same discharge of source water and the same flume-coolant temperatures, naleds developing in colder air grew thicker and covered less base area than did naleds developing in moderately cold air. A similar observation has been reported for naleds in Nature (Bukayev, 1973; Carey, 1973; Chistotinova and Tolstikhin, 1973). This observation is also supported by Equation (9). The equilibrium length, $l$, is inversely proportional to the magnitude of the heat fluxes, so naleds that grow in very cold air have shorter equilibrium lengths than do naleds that grow in moderately cold air. Because at any given time two naleds fed by equal discharges will have equivalent total masses, the naled that is longest will, on average, also be thinnest, and vice versa.

\section{SCALES OF TIME FOR NALED ICE GROWTH}

By using the equilibrium length, $l_{e}$, and the up-stream discharge, $q_{0}$, to non-dimensionalize Equation (8), it can be shown that time, $t$, should be normalized by the time-scale $t_{\mathrm{e}}$, defined as

$$
t_{\mathrm{e}}=\frac{\ell_{\mathrm{e}}^{2}}{100 q_{0}}
$$

The constant 100 is included to make $t / t_{\mathrm{e}}$ of order 1 for the laboratory data. The significance of $t_{\mathrm{e}}$ is that it is the time required to cover a unit width of naled surface, $l_{e}$ in length, with water of average depth $\ell_{\mathrm{e}} / 100$.
Similarly, a time-scale, $t_{\mathrm{S}}$, corresponding to $\ell_{\mathrm{S}}$, can be defined as

$$
t_{\mathrm{S}}=\frac{\ell_{\mathrm{S}}^{2}}{100 q_{0}} .
$$

\section{EXPERIMENTS}

Naleds were grown along the floor of a horizontal or slightly sloped flume under conditions of steady sourcewater discharge and steady air and flume-floor temperatures. As a naled grew and spread down-stream along the flume, the profiles of the water or slush surface on the naled and the underlying ice surface were recorded.

The naleds were grown in a $0.60 \mathrm{~m}$ wide, $0.30 \mathrm{~m}$ deep, and $12 \mathrm{~m}$ long refrigerated, tilting flume in the Low Temperature Flow Facility of IIHR. Details of the flume are shown in Figure 5. The side walls and floor of the flume are constructed of refrigeration panels through which ethylene-glycol coolant fluid can be circulated. The temperature of the coolant can be maintained at any value down to about $-15^{\circ} \mathrm{C}$. In Nature, the heat transfer from naleds occurs principally in the vertical direction, hence for the present study the side walls of the flume were lined with $0.05 \mathrm{~m}$ thick insulation panels to minimize heat transfer from the naleds to the side walls. The refrigerated flume has been more fully described by Kennedy ([1971]).

The experiments required steady water discharges as small as $0.002 \mathrm{l} / \mathrm{s}$. These discharges were obtained using the flume's auxiliary pump line to deliver water from the tail box to a small constant-head tank suspended from the ceiling at the up-stream end of the flume (see Fig. 5). From here the water was fed to a diffuser from which it was discharged uniformly across the flume. A gate at the up-stream end of the flume was closed and sealed so that the naled water could flow only in the down-stream direction. The discharge was measured volumetrically.

The temperature of the source water discharged into the diffuser was maintained between about $1^{\circ}$ and $3^{\circ} \mathrm{C}$ so

\begin{tabular}{|ll|}
\hline \multicolumn{1}{c|}{ KEY } \\
I & COOLANT INLET MANIFOLD \\
0 & COOLANT OUTLET MANIFOLD \\
1 & AUXILIARY PUMP $(1 / 6 \mathrm{HP})$ \\
2 & BYPASS VALVE \\
3 & CONSTANT-HEAD TANK \\
4 & WATER SUPPLY TO DIFFUSER \\
5 & FLUME HEADBOX \\
6 & FLUME GATE AND ACTUATOR \\
7 & FLUME TAILBOX \\
8 & DIFFUSER \\
9 & INSULATION PANELS \\
10 & DIRECTION OF COOLANT FLOW FOR UPSTREAM HOSES \\
& (OPPOSITE FOR DOWNSTREAM HOSES) \\
\hline
\end{tabular}
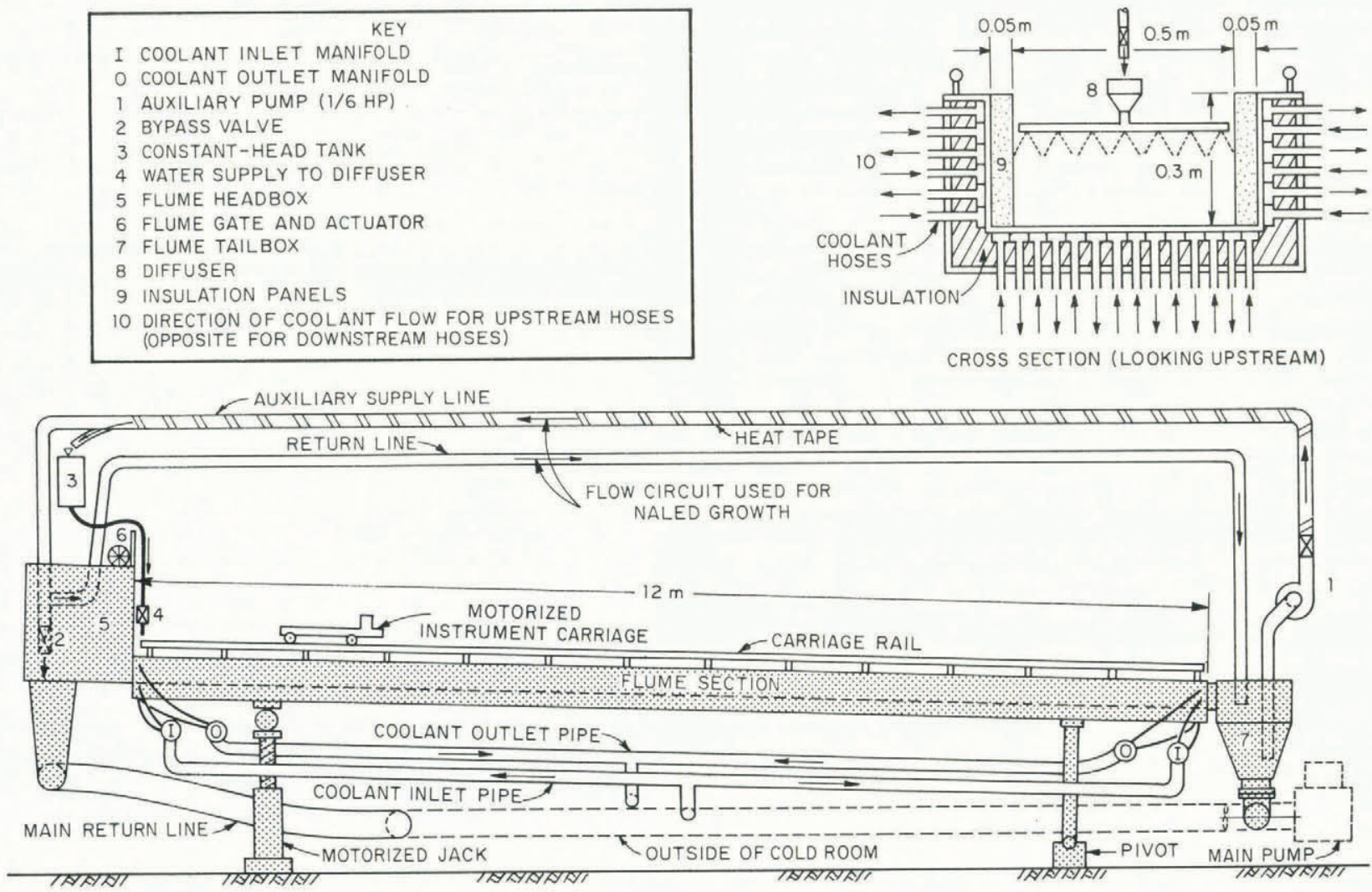

Fig. 5. Details of refrigerated, tilting flume. 
that the water temperature in the pool under the diffuser could be kept between $0^{\circ}$ and $0.5^{\circ} \mathrm{C}$. The source water was cooled by adding ice to the tail box, and by closing the by-pass valve in the head box so that water not fed to the constant-head tank was circulated through the cold return line back to the tail box. As needed, the source water was warmed by either adding warm water to the tail box, activating the heat tapes wrapped around the supply line, or opening the by-pass valve in the head box so that the recirculated water flowed into the main water-supply line, much of which is outside of the cold room.

The first step in conducting an experiment was to grow a level ice base on the floor of the flume. To do this, the air temperature in the refrigerated room was set slightly above $0^{\circ} \mathrm{C}$, the temperature of the flume floor was set well below $0^{\circ} \mathrm{C}$ (by circulating coolant fluid), the flume slope was set to zero (horizontal), and water was circulated through the flume. The heat flux through the flume floor caused a smooth, $3 \mathrm{~cm}$ thick ice base to form in about 4-12 h, depending on the coolant temperature. Then the flow was stopped and water was drained from the ice base, leaving it exposed to the air. The up-stream gate was closed and sealed, and the air and flume-floor (coolant) temperatures were adjusted to the requisite values for the forthcoming experiment. Various combinations of the values of the independent variables that are listed in Table I were used during the experiments.

\section{TABLE I. EXPERIMENTAL VARIABLES}

$\begin{array}{cccc}\begin{array}{c}\text { Air } \\ \text { temperature }\end{array} & \begin{array}{c}\text { Coolant } \\ \text { temperature }\end{array} & \begin{array}{c}\text { Source-water } \\ \text { discharge per } \\ \text { unit flume width }\end{array} & \begin{array}{c}\text { Flume } \\ \text { slope }\end{array} \\ T_{\mathrm{a}} & T_{\mathrm{b}} & q_{0} & S_{0} \\ { }^{\circ} \mathrm{C} & { }^{\circ} \mathrm{C} & 1 / \mathrm{s} / \mathrm{m} & \%\end{array}$

$$
-5,-10,-15 \quad 0,-1,-2 \quad 0.004,0.006,0.008
$$

An experiment was started when the air and floor temperatures attained the desired values. The flume slope was adjusted (if necessary), the source-water discharge was set and released through the diffuser over the up-stream end of the flume, and a naled developed over the up-stream part of the ice base on the flume floor. The progress of the naled as it spread down-stream was monitored by recording the times at which the naled's front reached various positions along the flume. Air temperature, coolant temperature, source-water discharge and temperature, and the naled's dimensions were measured regularly as the naled grew. A point gauge mounted on the flume's instrument carriage was used to measure the water surface and underlying ice-surface elevations at various positions along the longitudinal center line of the naled. The experiment was terminated either when the naled reached the down-stream (free overfall) end of the flume, or when the up-stream depth of the naled approached the depth of the flume, whichever condition occurred first. The time required for one experiment, from the first release of source water to the end of a test, varied from about 3 to $72 \mathrm{~h}$.

At the end of each test the naled was cut to expose and measure the layers of solid and slush ice that characterize cross-sections of naled ice.

\section{CHARACTERISTICS OF NALED SLUSH}

Water cooled rapidly to its freezing temperature as it flowed over, and fed, a naled. Ice crystals, in the form of platelets anchored to the ice surface grew into the flow. The accumulation and growth of the ice platelets transformed the free-surface laminar flow of water into a flow through a porous medium composed of ice. Herein, this mixture of ice and flowing water is referred to as naled slush.

Naled slush consists of a matrix of interlocked ice platelets. The growth of a slushy layer of naled ice is shown in Figure 6. This sequence of photographs illustrates the development of naled slush with time, from initially a few small platelets, to a denser matrix of larger platelets, and finally to a slush with a crusty surface of ice. The dark lines visible under the slush are metal seams, spaced about $4.4 \mathrm{~cm}$ apart, on the floor of the flume.

Water flowing over a naled becomes slightly supercooled before ice crystals form in the flow. In turbulent river flows, this supercooling is only a few hundreths of a Centigrade degree; the supercooling that occurs in shallow, laminar flows over naleds is likely of the same
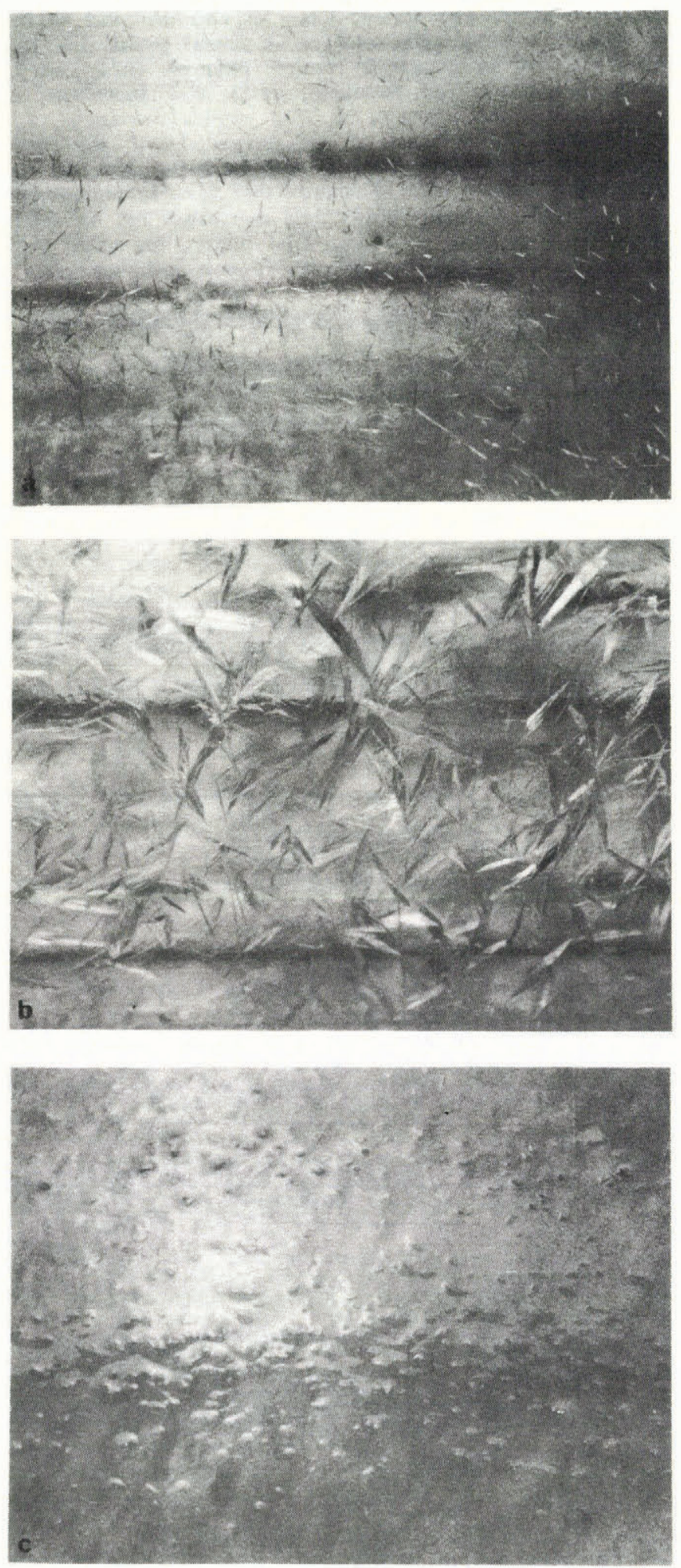

Fig. 6. Temporal development of naled ice slush. (a) A few relatively small ice platelets; (b) An increasing number of larger ice platelets; (c) Finally, a frozen surface over the slush. 
order of magnitude, or less. An attempt, during the present study, to measure accurately the temperature of supercooling was not entirely successful because of the inherent difficulty of measuring a slight temperature difference that persists for a very short time in an extremely shallow flow. However, it is reasonable to assume that the supercooling was less than $0.1^{\circ} \mathrm{C}$.

The literature on naleds appears to contain no observations concerning the form that ice crystals take when they grow in a slightly supercooled laminar flow over an ice base, but various investigators have discussed ice-crystal growth in slightly supercooled still water. Williamson and Chalmers (1966), for example, observed the growth of thin, disk-shaped crystals on a block of ice in slightly supercooled still water. The disks were attached to the block of ice at a point and retained their circular form as they grew.

As already mentioned, the ice crystals that formed on the ice base of a naled were observed to be platelets. They appeared to be attached at a point and may initially have been disk-shaped but, by the time they were large enough for their shape to be discerned, their upper boundary had been flattened by the free surface of the water. Beginning as small particles attached to the water-ice interface, the ice platelets grew rapidly into the flow, reaching the water-air surface in a matter of minutes. Initially, the platelets were distributed in complex, seemingly random, spatial arrays. The basal planes of the platelets were predominantly vertical, or parallel to the general direction of the heat flux $\phi_{\text {wa }}$.

In many respects, the development of the slush on a naled's surface is similar to the growth, described by Weeks and Ackley (1982), of the transition zone that is associated with the beginning of columnar ice-crystal growth for sea ice. For example, the orientation of the platelets in the naled slush seemed to be governed by the process that Weeks and Ackley termed "geometric selection". In this process, crystals that grow vertically downward from an initial cover of sea ice enjoy a preferred orientation that enables them to grow rapidly ahead of crystals with orientations less favorable for growth. The crystals that are less favorably oriented are, essentially, crowded out. Because the free surface of the water flow limited the vertical growth of the platelets, the slush development on the naleds did not progress to the columnar growth phase.

As the volumetric concentration of ice in the naled slush increased with time, the water flow over the naled was altered from a shallow free-surface flow to flow through a matrix, or porous medium, composed of ice crystals. The increasing impedance presented to the flow by the thickening ice matrix caused the up-stream depth of water to increase significantly such that the naled surface remained wet even as the ice platelets continued to grow taller. It was evident from observations of dye injected into the flow that water passed over the platelets that constituted the ice matrix, near the water surface, as well as percolating among the platelets.

\section{A COMPOSITE DESCRIPTION OF NALED ICE GROWTH}

What follows is a composite description of naled ice growth based on observations of laterally confined naleds grown in the laboratory flume; the description draws upon the foregoing discussions of the energy budget for naled ice growth and the characteristics of the naled slush.

The formation of a two-dimensional naled is portrayed sequentially in Figure 7 , in which the vertical scale is distorted by approximately one order of magnitude. The crosssections in Figure 7 were deduced from elevation measurements that were taken at regular positions along the naleds grown in the refrigerated flume. Figure 7 represents a synthesis of the available data.

In order to provide a perspective on the relative magnitudes of spread length and time associated with the different phases of naled ice growth, values of $\ell / \ell_{S}$ and $t / t_{\mathrm{S}}$ that approximately delineate the different phases shown are included in Figure 7. As discussed in section $4, l_{s}$ is a more useful length scale than $\ell_{e}$ for describing the layer-by-layer growth of a naled because the development

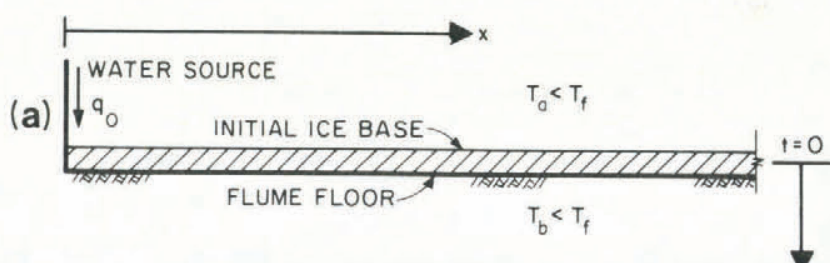

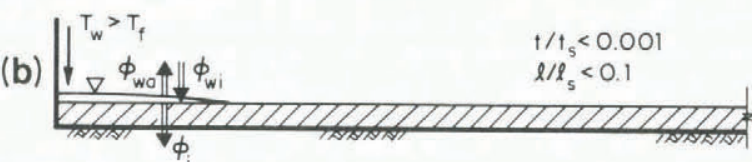

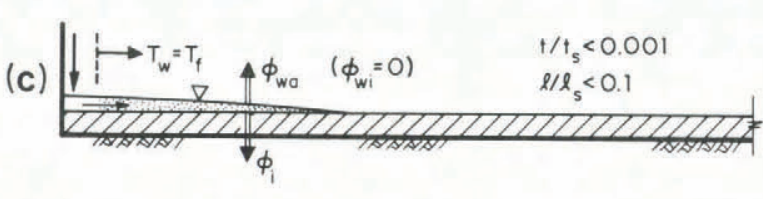

(d)
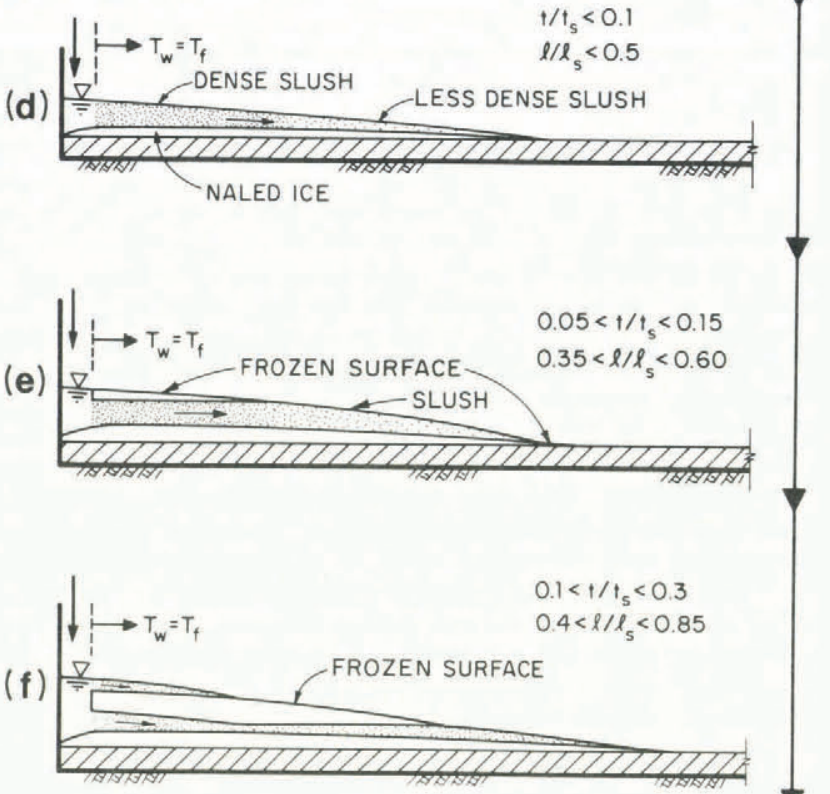

(g)

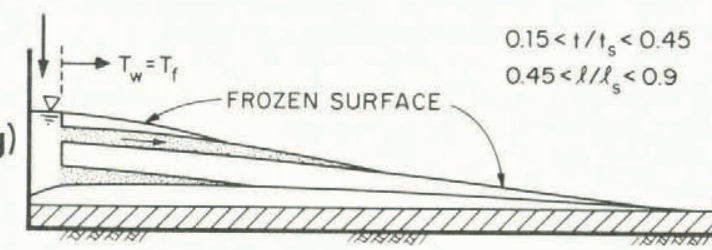

(h)

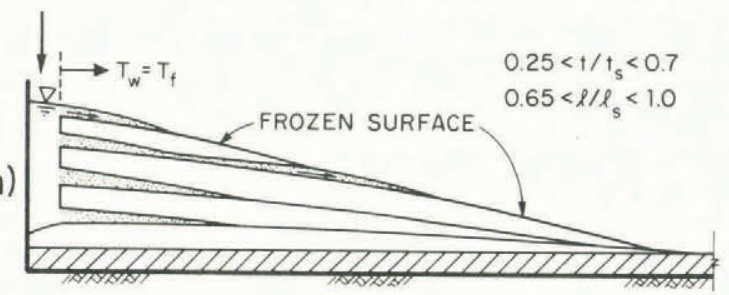

Fig. 7. Growth of a two-dimensional naled.

of naled slush and the freezing of its surface is governed principally by $\phi_{\text {wa }}$.

Naled ice growth was initiated in the flume by releasing water at the flume's up-stream end. Figure $7 \mathrm{a}$ illustrates the initial conditions: an ice base covered the flume floor and the air and base temperatures were less than $T_{\mathrm{f}}$. Although the ice base in Figure $7 \mathrm{a}$ is horizontal, the ensuing description is not limited to ice bases that are 
initially horizontal. Naleds that developed on small slopes $\left(S_{0} \leqslant 0.01\right)$ were observed to form in a similar manner.

The naleds developed initially in the manner illustrated in Figure $7 \mathrm{~b}$ and c. The water flowed slowly down-stream as a thin, sheet flow, cooled by heat transfer to the air, $\phi_{\mathrm{wa}}$, and to the ice base, $\phi_{\mathrm{wi}}$, until the water temperature was reduced to $T_{\mathrm{f}}$. Inevitably, the water that had been exposed longest to the frigid air and ice base cooled to $T_{\mathrm{f}}$ first. Consequently, ice platelets began appearing on the ice base near the down-stream front. This occurred very soon after a naled was started (within several minutes in the experiments). As depicted in Figure 7c, within a short period of time (several minutes) after the first platelets appeared, ice platelets formed on the ice base throughout the flow except for a small region up-stream, below the water source. Initially, the platelets were distributed relatively sparsely and were small (see Fig. 6a).

The next stage of naled development, depicted in Figure 7d, persisted for a significant period of time. The ice platelets in the naled slush continued to accumulate and grow during this period. The water flow was increasingly impeded so that the up-stream water depth was increased and the rate of spreading, already slow, was decreased. The volumetric concentration of ice in the down-stream slush was less than in the up-stream slush because the ice base down-stream had been covered by the flow for a shorter period of time than the ice base up-stream.

As depicted in Figure $7 e$, eventually the surface of the naled slush began to solidify up-stream. This marked the beginning of a continuous transition of the layer of naled slush into a solid layer of ice. The ice crust over the layer of naled slush became progressively thicker as the interstitial water in the slush froze. Meanwhile, the surface of the slush gradually solidified down-stream. Eventually, the layer of slush could no longer pass the entire discharge and, therefore, some of the water flowed slowly on to the frozen crust, as depicted in Figure $7 f$. In effect, a fresh naled fed by a smaller discharge was now developing on the ice cover. The intermediate solid layer continued to extend down-stream until it reached the flume's floor, and froze to it, closing the flow path through the underlying slush. Upstream, where a fresh layer of slush covered the frozen crust, this intermediate solid layer could not thicken further because it was sandwiched between isothermal slush layers at temperature $T_{\mathrm{f}}$. Down-stream from the surface layer of slush, the ice crust continued to thicken. Because the slush was insulated from the frigid air by the ice crust, ice platelets could no longer accumulate and grow in the underlying slush layer.

A solid crust of ice eventually formed up-stream over the uppermost layer of slush as illustrated in Figure $7 \mathrm{~g}$. This solid crust then gradually extended down-stream and thickened. The processes shown in Figure $7 \mathrm{e}, \mathrm{f}$, and $\mathrm{g}$ were repeated. A third slush layer developed on the surface of the second solid layer which, in turn, eventually froze to the ice base down-stream. Then, yet another solid layer formed up-stream (Fig. 7h). Presumably, this process could continue indefinitely so that a large number of layers would develop.

The flume constrained each naled so that its initial growth was two-dimensional, as is attested by the uniformity of the naled surface across the width of the flume in Figure 8a. However, the surface of the slush always began freezing and solidifying in the central third of the flume's width rather than uniformly across the flume (Fig. 8b). As the central part hardened and thickened, constricting the flow through the underlying slush, the water was diverted to the sides of the flume so that the slush near the flume side walls continued to develop. The subsequent naled surface was uneven, with a rough, dry center and wet, slushy sides. Strictly speaking, the naled was no longer two-dimensional. The observed diversion of flow away from the regions of a naled's surface that are solidifying is possibly a characteristic of the growth of a naled in Nature. In Nature, as a naled's surface would freeze, the source water would nearly always have the opportunity to move laterally, away from the regions of frozen slush.

During the phase of naled ice growth depicted in Figure $7 \mathrm{~d}$, the slush farthest up-stream would sometimes become disconnected from the ice base. When the base
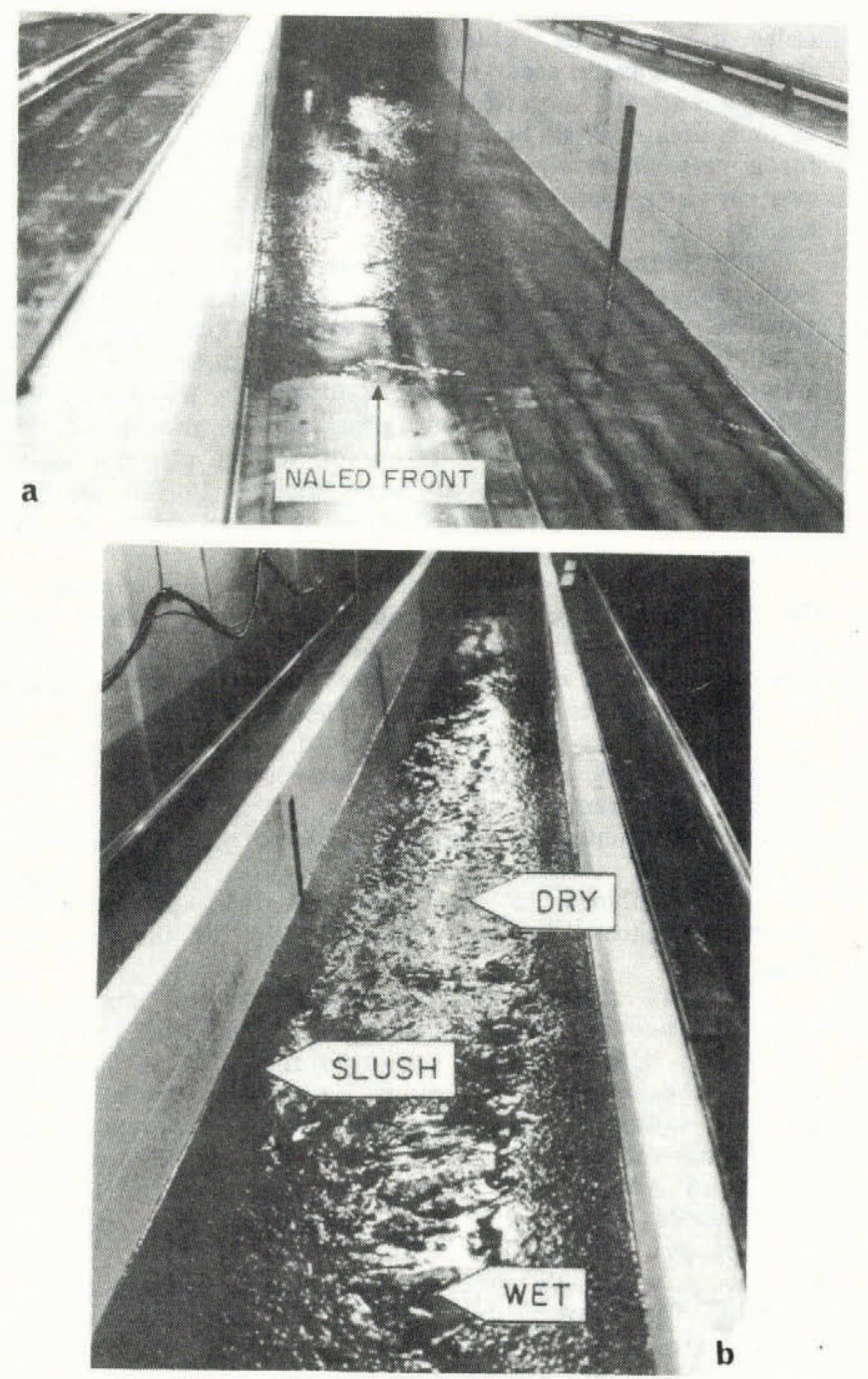

Fig. 8. Views of a naled growing in the refrigerated flume. (a) Two-dimensional naled; (b) Uneven surface freezing.

temperature, $T_{\mathrm{b}}$, was just below the freezing temperature, $T_{\mathrm{f}}$, the buoyancy force of the ice platelets sometimes overcame the attachment forces that anchored them to the ice base, and the entire matrix over a short length of naled would ascend to, and float at, the slowly rising water surface. New platelets would form on the ice base under the floating slush canopy. This suggests that the forces anchoring the platelets to the ice base possibly decrease with increasing $T_{\mathrm{b}}$ (decreasing $\phi_{\mathrm{i}}$ ).

\section{ICE LAMINATIONS}

Naled ice is usually laminated. Most of ten, the laminations found in naturally occurring naleds have consisted of solid layers of ice. However, unfrozen, slushy layers near the surface of a naled have been reported, and thin, porous layers of ice crystals in zones that were formerly occupied by liquid water, that has since been drained, are sometimes found (Carey, 1973). Solid layers of ice and layers of unfrozen slush were observed during the present study.

Figure 9a illustrates solid layers of ice in a piece of naled ice taken from a naled that was grown in the flume. Adjacent solid layers of ice developed in a naled at those positions where each successive slush layer on the naled's surface was exposed to the frigid air for a long enough time to enable the slush layer to freeze solid over its entire depth. A slush layer ceased solidifying when a new slush layer, spreading slowly down-stream, covered the frozen surface of the underlying slush layer (thereby insulating it from $\left.\phi_{\text {wa }}\right)$. Consequently, adjacent solid layers of ice were likely to be found somewhat down-stream from a naled's water source (see Fig. 7h). Up-stream, near a naled's water source, several alternating layers of solid and slush ice were 

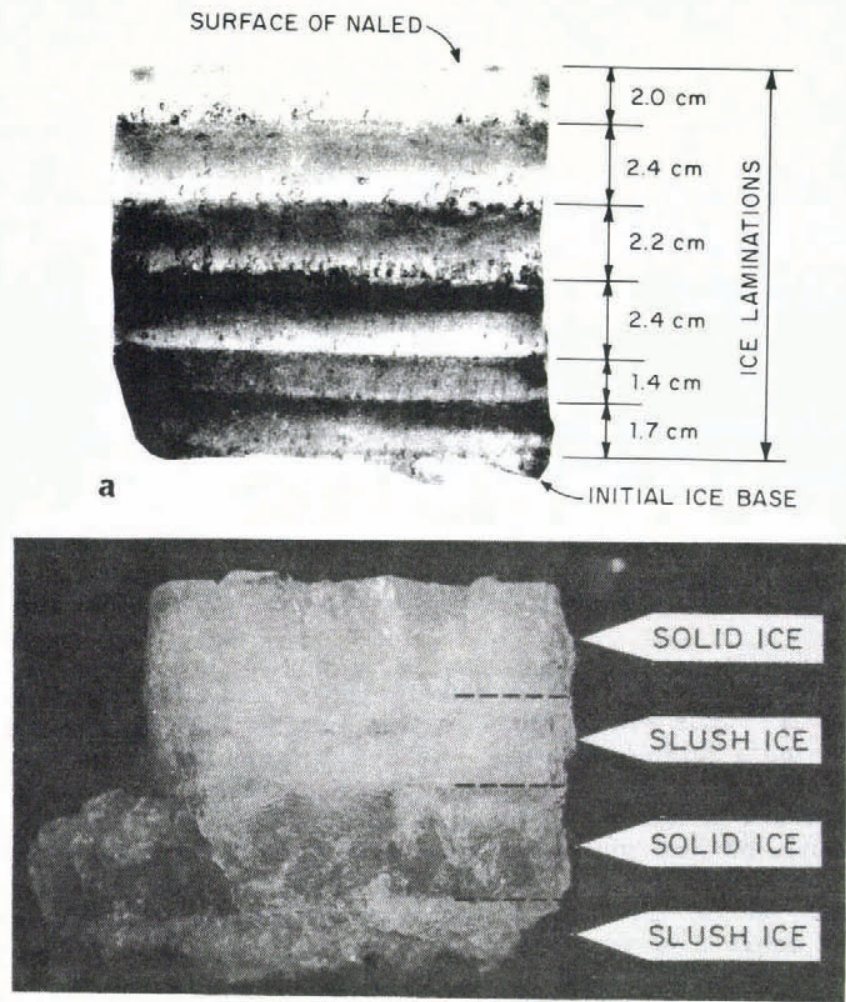

Fig. 9. Ice laminations in naled ice. (a) Adjacent solid layers of ice in a piece of naled ice; (b) Alternating layers of solid and slush ice.

sometimes found; a sample is shown in Figure $9 \mathrm{~b}$. Because the surface layers spread very slowly down-stream, the upstream region over which alternating layers of solid and slush ice were sometimes found was quite small relative to the spread length of a naled (the proportion of the naled in Figure $7 \mathrm{~h}$ that has alternating layers is exaggerated for the sake of illustration).

\section{CONCLUSIONS}

A comprehensive description of naled ice growth, based on laboratory observations of laterally confined naleds grown in a refrigerated flume, is presented. The laboratory naleds spread and thickened in a complex, layer-by-layer manner. The first phase of their growth was approximately twodimensional, but their later growth was complicated somewhat by boundary effects due to the side walls of the flume.

The heat-flux components that govern naled ice growth are identified and expressions given for each (Equations (1), (2), (3), (5), and (6)). A naled spread length, which the authors call the equilibrium length (Equation (9)), is derived from the conservation-of-mass principle applied to the water flowing on the surface of a naled. Based on the equilibrium-length $\left(l_{e}\right)$ concept, length- and time-scales useful for discussing distinct phases of naled ice growth are introduced (Equations (10) and (12)).

The slush that forms to balance the surface heat flux, in the flow of water over a naled is described as ice crystals, in the form of platelets anchored to the ice surface, which grow into the flow.

A composite description of naled ice growth is presented and is summarized schematically in Figure 7. The continuing cyclic process by which ice layers form on the surface of slush layers results in the ice laminations that are a feature of naled ice.

Finally, the laminations themselves are discussed. Both solid layers of ice and layers of unfrozen slush were observed in the laboratory and examples are shown in Figure 9.

\section{ACKNOWLEDGEMENTS}

This research was supported by the National Science Foundation (NSF grant CEE81-09252). We also wish to thank the U.S. Army Cold Regions Research and Engineering Laboratory for permitting the use and adaption of Figures 2, 15, and 16 from Carey's (1973) monograph.

\section{REFERENCES}

Alekseyev, V.R., and others, eds. 1973. Siberian naleds. Hanover, NH, U.S. Cold Regions Research and Engineering Laboratory. (Draft translation 399.)

Ashton, G.D. 1978. River ice. Annual Review of Fluid Mechanics, Vol. 10, p. 369-92.

Ashton, G.D. Unpublished. The formation of ice ripples on the underside of river ice covers. [Ph.D. thesis, University of Iowa, 1971.]

Baranowski, S. 1982. Naled ice in front of some Spitsbergen glaciers. Journal of Glaciology, Vol. 28, No. 98, p. 211-14.

Bengtsson, L. 1982. Heat losses from an open water surface at very low air temperatures - a laboratory experiment. (In IAHR. International Association for Hydraulic Research. International Symposium on Ice, ... 1981. Proceedings. Vol. 1. Quebec, Université Laval, p. 55-64.)

Carey, K.L. 1970. Icing occurrence, control, and prevention - an annotated bibliography. CRREL Special Report 151.

Carey, K.L. 1973. Icings developed from surface water and ground water. CRREL Monograph III-D3.

Chistotinova, L.T., and Tolstikhin, O.N. 1973. Certain questions in formation of chemical composition of naled ice (an example of naled in Ulakhan-Taryn and central Yakutia). (In Alekseyev, V.R., and others, eds. Siberian naleds. Hanover, NH, U.S. Cold Regions Research and Engineering Laboratory, p. 172-83. (Draft translation 399.))

Gavrilova, M.K. 1973. Radiation and heat balances, thermal regime of an icing. (In The role of snow and ice in hydrology. Proceedings of the Banff symposia, September 1972. A contribution to the International Hydrological Decade, Vol. 1. Paris, UNESCO; Geneva, WMO; Budapest, IAHS, p. 496-504. (Publication No. 107 de l'Association Internationale d'Hydrologie Scientifique.))

Haynes, F.D., and Ashton, G.D. 1979. Turbulent heat transfer in large aspect channels. CRREL Report 79-13.

Hsu, K.S. Unpublished. Spectral evolution of ice ripples. [Ph.D. thesis, University of Iowa, 1973.]

Kane, D.L. 1981. Physical mechanics of aufeis growth. Canadian Journal of Civil Engineering, Vol. 8, No. 2, p. 186-95.

Kennedy, J.F. [1971.] The Iowa low temperature flow facility. (In I.A.H.R. Symposium: Ice and its Action on Hydraulic Structures, Reykjavik, Iceland, 8-10 September 1970. [Delft, International Association of Hydraulic Research], Paper 1.2.)

Schohl, G.A., and Ettema, R. 1986. Naled ice growth. Iowa City, IA, University of Iowa. Institute of Hydraulic Research. (Report No. 297.)

Sloan, C.E., and others. 1976. Icings along the trans-Alaska pipeline route, by C.E. Sloan, C. Zenone, and L.R. Mayo. U.S. Geological Survey. Professional Paper 979.

Sokolov, B.L. 1979. Formation of river icing. Soviet Hydrology. Selected Papers, Vol. 18, No. 1, p. 53-57.

Wankiewicz, A. 1984. Analysis of winter heat flow in an ice-covered Arctic stream. Canadian Journal of Civil Engineering, Vol. 11, p. 430-43.

Weeks, W.F., and Ackley, S.F. 1982. The growth, structure, and properties of sea ice. CRREL Monograph 82-1.

Williamson, R.B., and Chalmers, B. 1966. Morphology of ice solidified in undercooled water. (In Peiser, H.S., ed. Crystal growth; proceedings of International Conference on Crystal Growth, Boston, June 1966. Oxford, Pergamon Press, p. 739.) 